\title{
Study on Side-entering Agitator Flow Field Simulation in Large Scale Biogas Digester
}

\author{
Li Xinxin ${ }^{1}$, Cao Yadong ${ }^{1}$, Huang Zhenfeng ${ }^{1}$, Liang Jingfu' ${ }^{2}$, Cheng Gang ${ }^{2}$, and Pan Rui ${ }^{2}$ \\ ${ }^{1}$ School of Mechanical Engineering, Guangxi University, China 530004 \\ ${ }^{2}$ Guangxi Bossco Environmental Protection Technology Co.,Ltd, China 530004
}

\begin{abstract}
Based on the CFD software Fluent, the multi-reference system method, the RNG $\kappa-\varepsilon$ turbulence model and the pressure-velocity coupled SIMPLEC algorithm are applied to simulate the flow field of a single side-entering agitator in a large biogas digester. And the impact of different installation angle, agitator-to-bottom height, agitating speed and agitator diameter on the agitating power, the effective area percentage and the effective power ratio are analyzed. The results show that: 1 ) when the agitating speed is more than $450 \mathrm{r} / \mathrm{min}$ and the agitating diameter is more than $750 \mathrm{~mm}$, the effective area percentage reaches the maximum value; 2) when the horizontal angle is $30^{\circ}$, the agitating effect is the best; 3 ) when the vertical angle is inclined to the bottom and the agitator-to-bottom height is less than $8 \mathrm{~m}$, it is helpful to prevent the sediment from appearing. The results of numerical simulation provide a theoretical basis for the design to optimize the agitator.
\end{abstract}

\section{Introduction}

With the rapid development of computational fluid dynamics (CFD) in recent years, some scholars at home and abroad have applied computational fluid dynamics technology to the optimization design of mixing tank through numerical simulation. At present, the numerical simulation of vertical agitation is common, but not the research on the side-entering agitator [1-3]. Wesselingh[4] studied the mixing time of different size single-side agitator, and analysed flow field with multiple factors such as paddle type, propeller angle, Reynolds coefficiency, and so on. The simulation results are in agreement with the experimental results. Asghar[5] studied the effect of the different factors on mixing time of two kinds of crude oil with one side-entering agitator through RNG turbulence model. Fang Jian[6-7] carried out the numerical simulation of the fluid flow and mixing process in the tank with 4 side-entering agitators, and the power curve was obtained. Also, the influence of different tracer feeding point, monitoring point position and agitator shaft deflection angle on the mixing time were studied. Zhang Linjin[8] used computational fluid dynamics (CFD) technology to simulate the side-entering agitator flow filed in the bottom of the flue gas desulfurization absorption tower, the influence of the agitating speed and agitating paddle installation angle and other factors on the three-dimensional flow field were studied. Zheng Xiaodong[9] studied the effect of the installation position, the ventilation rate, the solid particle concentration and the liquid level on the particle suspension performance in the side-entering mixing tank.
Chen $\mathrm{Jia}[10]$ uses the computational fluid dynamics technique to calculate the mesoscopic macroscopic flow field in the large-scale side-entering agitated tank with the diameter and height of $13 \mathrm{~m}$, and the effects of different agitating speed, agitating angle and number on the distribution of low dead zone in the kettle were investigated at the same time. In summary, there are some research reported on the side entering agitator, but a thorough study on single agitator is still needed, which should analysis the parameters of agitating system and provide the base for optimization design.

In this paper, a simplified model of the biogas digester with a single side-entering agitator is built and applied to simulate flow field. With the help of CFD software Fluent, the impact of horizontal and vertical installation angles, height from tank bottom, agitator speed and diameter on power consumption and effective area are studies, which provided reference for the optimization design of side entering agitator and its practical application.

\section{Model and Simulations}

\subsection{Model}

The calculation model of this paper is based on a simplified large-scale biogas mixing tank designed by one of the authors' cooperative company. The cylinder tank is with $16 \mathrm{~m}$ diameter and $16 \mathrm{~m}$ high. For the single side entry agitator, the angle of the agitator between the $\mathrm{XZ}$ plane and the negative direction of the $\mathrm{X}$ axis is set to 
horizontal angle $\alpha$, and the positive direction of the $\mathrm{Y}$ axis is defined as positive. The angle of the agitator between the XY plane and the negative direction of the $\mathrm{X}$ axis is set to the vertical angle $\beta$, and the negative direction of the $Z$ axis is defined as negative. The distance between the agitator's agitating shaft and the bottom of mixing tank is defined as the agitator-tobottom height $h$, as shown in Fig. 1. The agitator type uses the industry standard three-leaf right-handed propeller(HG/T 3796.8-2005), and the simplified threedimensional model of the agitator is shown in Fig. 2. The shaft length of the agitator inserted into the tank is fixed at $2.8 \mathrm{~m}$ as required.

In order to simplify the calculation, it is assumed that the mixing tank is a closed cell body filled with liquid, and no feed port and waste discharge port are provided. The three-dimensional physical model of numerical simulation is established by UG, and then, imported into Fluent, preparing for simulations.

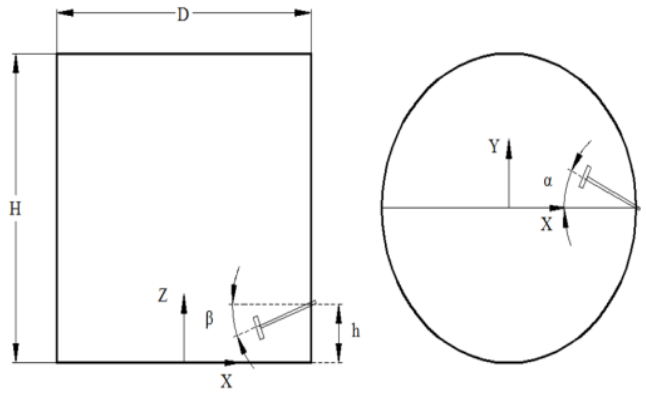

Figure 1. Schematic diagram of mixing model

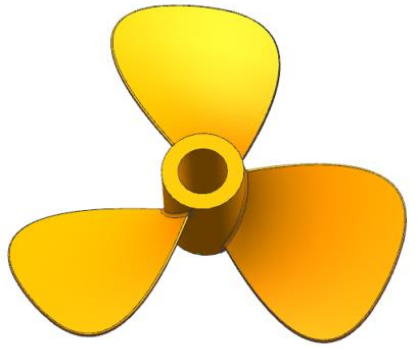

Figure 2. Three dimensional model of propeller agitator

\subsection{Simulations}

\subsubsection{Design experiment}

There are several main factors which are most important for the agitating power and the agitating effect of the side-entering agitator, such as viscosity of the liquid in the mixing tank, agitating diameter, agitating speed, agitator-to-bottom height, and angle between agitating shaft and tank. In this paper, the solid content in in the anaerobic tank is about $10 \%$, and the temperature in the tank is about $60{ }^{\circ} \mathrm{C}$. According to Liu $\mathrm{Yi}^{[11]}$ 's results, it can be seen that the viscosity of the anaerobic tank is about $0.05 \mathrm{~Pa}^{*} \mathrm{~s}$, which belongs to the low viscosity liquid. Hence, compared with other factors, the viscosity impact on agitating flow field and agitating power would be negligible. As a result, five simulation parameters, horizontal angle $\alpha$, vertical angle $\beta$, agitator-to-bottom height $\mathrm{h}$, agitating speed $\mathrm{n}$, and agitating diameter $\mathrm{d}$, are selected to analyse, and their impacts on flow field and agitating power are simulated separately. Table 1 lists the simulation values for each single factor.

Table 1. Design of test parameters

\begin{tabular}{|c|c|c|}
\hline Experime & \multicolumn{2}{|c|}{ Test parameters } \\
\hline \multirow[t]{2}{*}{1} & $\begin{array}{c}\text { Horizontal angle } \\
\alpha /{ }^{\circ}\end{array}$ & $\begin{array}{l}0 、 5 、 10 、 15 、 20 、 \\
25 、 30 、 35 、 40\end{array}$ \\
\hline & Fixed value & $\begin{array}{l}\beta=0^{\circ} 、 h=2.5 \mathrm{~m} 、 \mathrm{n}=360 \\
\mathrm{r} \cdot \mathrm{min}^{-1} 、 \mathrm{~d}=650 \mathrm{~mm}\end{array}$ \\
\hline \multirow[t]{2}{*}{2} & $\begin{array}{c}\text { Vertical angle } \\
\beta /{ }^{\circ}\end{array}$ & $\begin{array}{l}-40 、-30 、-20 、-10 、 \\
0 、 10 、 20 、 30 、 40\end{array}$ \\
\hline & Fixed value & $\begin{array}{l}\alpha=0^{\circ} 、 \mathrm{~h}=2.5 \mathrm{~m} 、 \mathrm{n}=360 \\
\mathrm{r} \cdot \mathrm{min}^{-1} 、 \mathrm{~d}=650 \mathrm{~mm}\end{array}$ \\
\hline \multirow[t]{2}{*}{3} & $\begin{array}{l}\text { Agitator-to- } \\
\text { bottom height } \\
\mathrm{h} / \mathrm{m}\end{array}$ & $\begin{array}{c}2 、 4 、 6 、 8 、 10 、 12 、 \\
14\end{array}$ \\
\hline & Fixed value & $\begin{array}{rl}\alpha=20^{\circ} 、 & \beta=20^{\circ}, \mathrm{n}=360 \\
\mathrm{r} \cdot \mathrm{min}^{-1} 、 & d=650 \mathrm{~mm}\end{array}$ \\
\hline \multirow[t]{2}{*}{4} & $\begin{array}{l}\text { Stirring speed } \\
\mathrm{n} / \mathrm{r} \cdot \mathrm{min}^{-1}\end{array}$ & $\begin{array}{c}200 、 250 、 300 、 400 、 \\
450 、 500\end{array}$ \\
\hline & Fixed value & $\begin{array}{c}\alpha=30^{\circ} 、 \beta=0^{\circ} 、 \mathrm{~h}=2.5 \mathrm{~m} 、 \\
\mathrm{~d}=650 \mathrm{~mm}\end{array}$ \\
\hline \multirow[t]{2}{*}{5} & $\begin{array}{c}\text { Agitating diameter } \\
\mathrm{d} / \mathrm{mm}\end{array}$ & $\begin{array}{c}400 、 450 、 500 、 550 、 \\
600 、 650 、 700 、 750 、 800\end{array}$ \\
\hline & Fixed value & $\begin{array}{c}\alpha=30^{\circ} 、 \beta=0^{\circ} 、 \mathrm{~h}=2.5 \mathrm{~m} 、 \\
\mathrm{n}=360 \mathrm{r} \cdot \mathrm{min}^{-1}\end{array}$ \\
\hline
\end{tabular}

\subsubsection{Solution}

The software Fluent provides three modelling methods to solve the problem with coexistence of stationary and moving regions, namely: multiple reference system (MRF) model, mixed plane model and sliding mesh model. This paper adopts the multi-reference method for steady-state calculation: firstly, the mixing device is divided into two non-overlapping regions, representing for agitating region and the external region, respectively; secondly, calculations are carried out in these two regions with two different reference systems-the paddle blade and its adjacent fluid areas with rotated coordinate system, and the other fluid regions with the stationary coordinate system. It is noted that the interface of the two regions is set to the inner surface (interface), the blade surface, the bottom of the tank and the outer surface of the pool set to walls (wall), and the upper surface of the tank set to free exit (outflow).

The RNG $\kappa-\varepsilon$ turbulence model is applied to predict the effects of buoyancy, strong rotation, high shear and low Reynolds number. The anaerobic fermentation broth 
is replaced with incompressible water as the working medium, and its viscosity is set as $0.05 \mathrm{~Pa} \cdot \mathrm{s}$. Because of self-weight of the liquid, the $\mathrm{Z}$-axis negative acceleration is $9.8 \mathrm{~m} / \mathrm{s}^{2}$. The SIMPLEC algorithm and the second-order windward difference scheme are used to improve convergence speed and accuracy of the unstructured grid. When the residual becomes stable or less than $1 \times 10^{-3}$, it is regarded as stable statue or calculation completion.

\section{Results and discussion}

\subsection{Power}

The size of the agitating power is an important indicator of the degree of mixing and flow of the material in the mixing tank. It is also the key basis for selecting the motor power. The agitator is subjected to pressure and viscous forces in the flow field so that the power of the agitator can be calculated by the torque acting on the blade ${ }^{[12]}$. The torque on the agitator and the velocity of the blades in the rotational tangential direction are obtained, and the power is calculated through Eq.(1).

$$
P=M \omega=M \times 2 \pi n / 60
$$

Where, $\mathrm{M}$ represents torque, $\omega$ represents angular velocity, and $\mathrm{n}$ represents speed.

When the calculation is stable, the torque on the agitator can be obtained by post-treatment in Fluent, then is applied to calculated the agitating power. The simulation power consumptions of the test groups, are shown as (a) to (e) in Fig. 3, corresponding to No. 1 to 5 group.
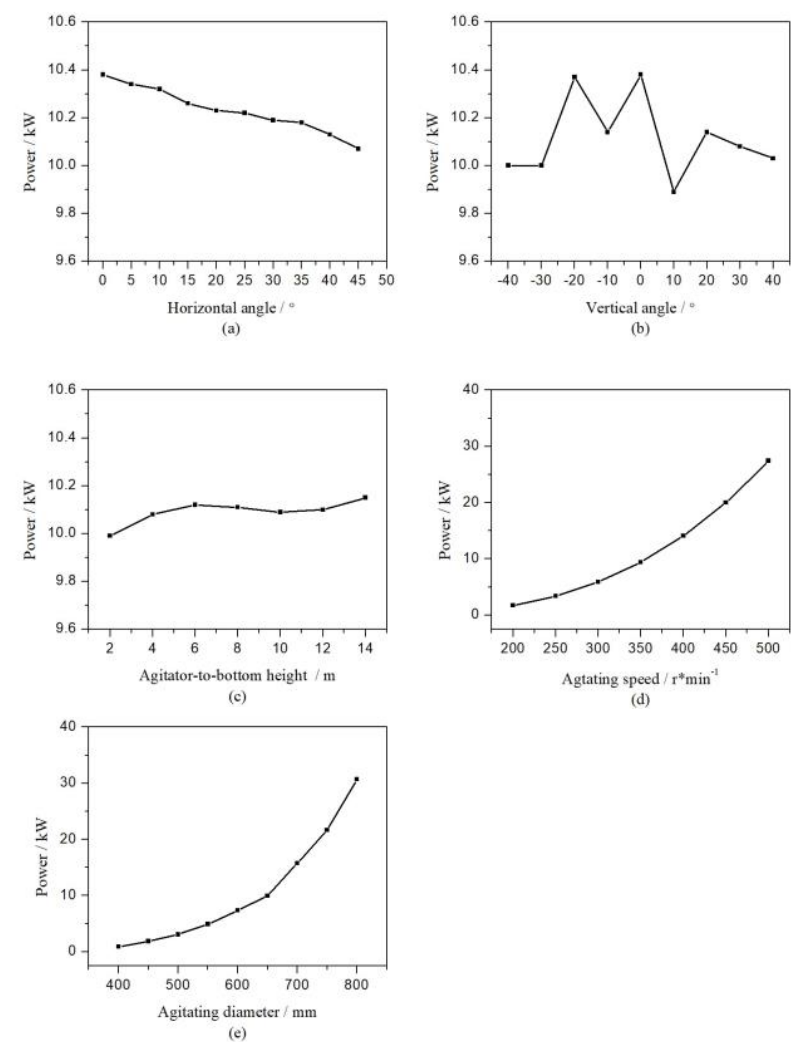

According to Fig. 3(a), the agitating power is gradually reduced as the horizontal angle increases from $0^{\circ}$ to $40^{\circ}$. With the vertical angle increasing or decreasing, the agitating power does not change with the same direction, but just fluctuated around $10 \mathrm{~kW}$ in a small range, as seen in Fig. 3(b). From Fig. 3(c), the influence of the agitatorto-bottom height on the agitating power is very small. However, from Fig. 3(d) - (e), with the increase of the agitating speed and the agitating diameter, the agitating power increases rapidly in the form of parabola.

In summary, simulation results show that:

1) A certain horizontal angle is conducive to reducing the agitating power.

2) The vertical angle and the agitator-to-bottom height have little effect on the agitating power.

3) The change of agitating speed and agitating diameter has great influence on the agitating power, the agitating power increases rapidly with the increase of agitating speed and agitating diameter; hence, reducing the agitating speed and agitating the diameter can effectively reduce the agitating power.

\subsection{The effective area percentage}

According to the People's Republic of China urban construction industry standards (CJ/T 109-2007): the area where the water flows greater than $0.3 \mathrm{~m} / \mathrm{s}$ is known as the effective working area of the agitation. To meet the requirement, in this paper, the area where the fluid flow rate is no less than $0.3 \mathrm{~m} / \mathrm{s}$ is set as the effective agitation area, i.e., in which the mixing can be effectively agitated and the precipitation is prevented. The percentage of effective agitation zone in whole agitated area is referred as the effective area percentage, that is, the greater the percentage, the better the agitating effect.

After the numerical simulation, the effective area percentage of each test group can be worked out by postprocessing. The simulation results are plotted as shown in Figure 4. As can be seen from Fig. 4(a), with the increase of the horizontal angle, the effective area percentage increases from $3 \%$ to $16 \%$, and then reduces to $5 \%$, the minimum value at $5^{\circ}$ and the maximum at $30^{\circ}$. Seen from Fig. $4(\mathrm{~b})$, as the vertical angle changes from $-40^{\circ}$ to $40^{\circ}$, the effective area percentage increases first and then reduces, showing the maximum value $7 \%$ at $-20^{\circ}$; From Fig. 4(c), with the increase of the agitator-to-bottom height, the effective area percentage increases first and then decreases, and the effective area percentage is $8 \%$ at the bottom height of $6 \mathrm{~m}$ and the agitating effect is the best; And from Fig. 4(d), with the increase of the agitating speed, the effective area percentage increases slowly with the speed between $200 \mathrm{r} / \mathrm{min}$ and $300 \mathrm{r} / \mathrm{min}$ and then increases rapidly between $300 \mathrm{r} / \mathrm{min}$ and 400 $\mathrm{r} / \mathrm{min}$, finally reaches its maximum value at $450 \mathrm{r} / \mathrm{min}$ and tends to be stable. From Fig. 4(e), as the agitating diameter increasing, the effective area percentage increases as well, and reaches its maximum value at 750 $\mathrm{mm}$ and tends to be stable.

Figure 3. Agitating power curve 

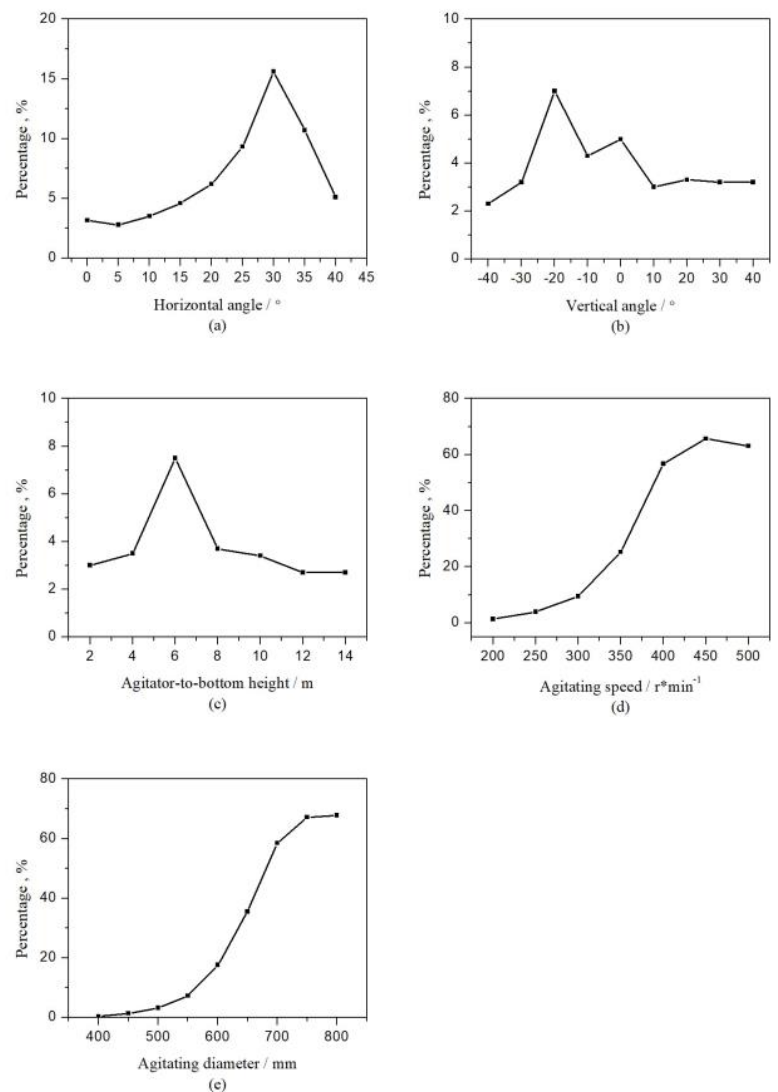

Figure 4. Effective area percentage curve

Simulation results show that:

1) When the horizontal angle, the vertical angle and the bottom height respectively are $10^{\circ} \sim 40^{\circ},-30^{\circ} \sim 0^{\circ}$ and $2 \mathrm{~m} \sim 8 \mathrm{~m}$, the effective area percentage is relatively large and the agitating effect is better.

2) When the agitating speed is between $300 \mathrm{r} / \mathrm{min}$ and $450 \mathrm{r} / \mathrm{min}$ or the agitating diameter is between $550 \mathrm{~mm}$ and $700 \mathrm{~mm}$, increasing the agitating speed or agitating diameter is very beneficial to improve the effective area percentage.

3) When the agitating speed is greater than $450 \mathrm{r} / \mathrm{min}$ or the agitating diameter is greater than $750 \mathrm{~mm}$, increasing the agitating speed or agitating diameter will not only reduce the effective area percentage, but also increase the agitating power.

\subsection{The effective power ratio}

Combining the mixing power and the effective area percentage, the ratio of the effective area percentage to the agitating power can be used to characterize the efficiency of unit agitating power, referred to as the effective power ratio. The larger the ratio is, the better the agitating efficiency. From Fig. 5(a), when the vertical angle between $-30^{\circ}$ and $0^{\circ}$, the effective power ratio is larger, but for the other angles, the ratio is smaller. From Fig. 5(b), when the agitating speed is between 300r/min and $500 \mathrm{r} / \mathrm{min}$, the effective power ratio is relatively large and the ratio for other rotational speed is small. As can be seen from Fig. 5(c) when the agitating diameter is between $600 \mathrm{~mm}$ and $750 \mathrm{~mm}$, the effective power ratio is relatively large and the ratio for the other mixing diameter is small.
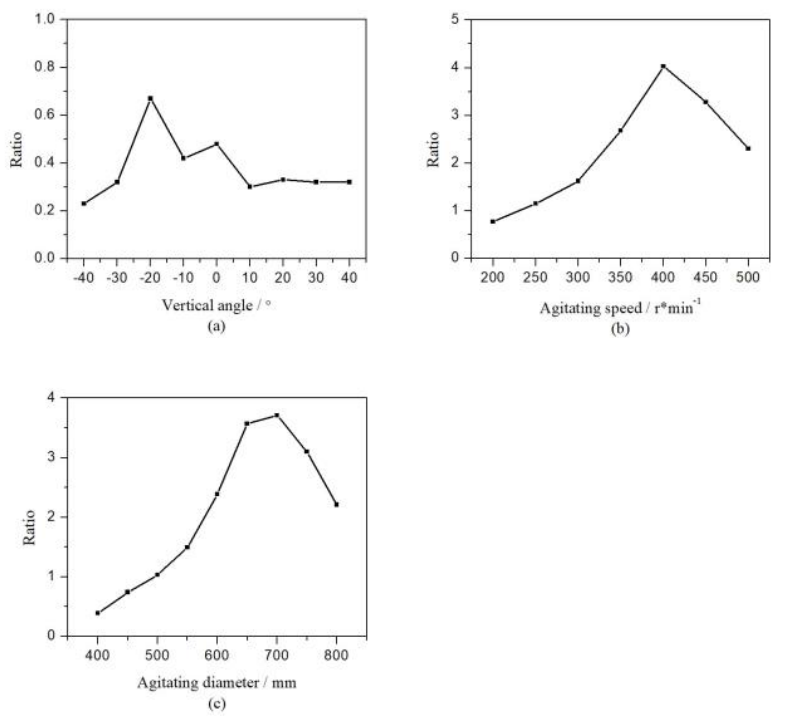

Figure 5. Effective power ratio curve

It can be known from above simulation results that:

When the vertical angle lies between $-30^{\circ}$ and $0^{\circ}$, the agitating efficiency would be better if the agitating speed is in the range of $300 \mathrm{r} / \mathrm{min}$ and $500 \mathrm{r} / \mathrm{min}$ or the agitating diameter in the range of $600 \mathrm{~mm}$ and $750 \mathrm{~mm}$.

\section{Conclusion}

In this paper, the agitating process of the single sideentering agitator in the large anaerobic agitated tank was simulated by Fluent software. By analyzing the influence of each factor on the agitating power, the effective area percentage and the effective power ratio is worked out, and the conclusions are drawn:

1) The horizontal angle has little effect on the agitating power, but its effect on the effective area percentage is relatively significant. When the horizontal angle is $30^{\circ}$, the effective area percentage is the largest and the agitating flow field is the best.

2) The effect of vertical angle on the agitating power is very small. When the vertical angle between $-30^{\circ}$ and $0^{\circ}$, the agitating efficiency is relatively high.

3) The effect of agitator-to-bottom height on the agitating power is very small. When the agitator-to-bottom height is less than $8 \mathrm{~m}$, it would be helpful to improve the effective area percentage and prevent the appearance of the precipitation.

4) The agitating speed and the agitating diameter have great impacts on the agitating power and the effective area percentage. Increasing these two factors can effectively increase the effective area percentage. When the agitating speed lies between $300 \mathrm{r} / \mathrm{min}$ and $500 \mathrm{r} / \mathrm{min}$ and the agitating diameter between $600 \mathrm{~mm}$ and $750 \mathrm{~mm}$, the agitating efficiency is better.

\section{References}

1. G. Montante, K. C. Lee, A. Brucato, et al. Numerical simulations of the dependency of flow pattern on 
impeller clearance in stirred vesseds[J]. Chem Eng Sci, 2001, 56(12):3751-3770.

2. A. Kukekova, M. Mostek, M. Jahoda, V. Machon. CFD prediction of flow and homogenization in a stirred vessel: Part I vessed with one and two inpellers $[\mathrm{J}]$. Chemical Engineering and Technoloyg, 2005, 28(10):1125-1133.

3. Mingzhong L. Gracme W. Derek Wilkinson, et al. Scale up study of retreat curve impeller stirred tanks using LDK measurements and CFD simulation[J]. Chem Eng Sci. 2005, 108(1-2):81-90.

4. Wesselingh J A. Mixing of Liquids in Cylindrical Storage Tanks with Side-entering Propellers[J]. Chem Eng Sci, 1975, 30(8): 973-981.

5. Asghar A D. Masoud R. CFD simulation of homogenization in large-scale crude oil storage tanks[J]. J Pet Sci Eng, 2004, 43(3-4): 151-169.

6. Fang Jian, Sang Zhifu, Yang Qubao, Numerical simulation of three-dimensional flow field of the side entering agitator[J]. Petroleum Machinery, 2009, 37(1):30-34.

7. Fang Jian, Ling Xiang, Sang Zhifu, et al. CFD simulation of the mixing process of side entry mixer [C].Proceedings of the 2010 annual meeting of the
Chinese Society for Environmental Science (volume fourth). 2010.

8. Zhang Linjin, Chen Gongguo, Ye Xuchu.NumericaI Simulation of Flow Field in Side-Entering Stirred Reactor[J]. Chemical Reaction Engineering and TechnoIogy, 2011, 27(2):97-102.

9. Zheng Xiaodong, Huang Xiongbin, Du Rongli. Suspension of Solid Particles by Side-entering Agitators $[\mathrm{J}]$. The Chinese Journal of Process Engineering, 2009, 9(3):417-423.

10. Chen Jia, Xiao Wende. Numerical simulation of turbulent flow field in industrial-scale side-entering stirred $\operatorname{tank}[\mathrm{J}]$.Chemical Engineering, 2013, 41(8):38-42.

11. Liuyi. High concentration of biogas fermentation material mixture stirring and influencing factors of research[D]. Chinese Academy of Agricultural Sciences, 2009

12. Chen Nianjin. The Power Calculation of the Stirrer Based on CFX[J]. Chemical equipment technology 2014, 35(3):27-29.

13. CJ/T 109-2007, Diving mixer[S]. 